\title{
Nitric Oxide Reverses Acute Hypoxic Pulmonary Hypertension in the Newborn Piglet
}

\author{
PHILIP C. ETCHES, NEIL N. FINER, KEITH J. BARRINGTON, ANDREW J. GRAHAM, AND \\ WINSTON K. Y. CHAN \\ Departments of Pediatrics [P.C.E., N.N.F., K.J.B.] and Surgery [A.J.G., W.K.Y.C.J, University of Alberta and \\ Department of Newborn Medicine [P.C.E., N.N.F., K.J.B.], \\ Royal Alexandra Hospital, University of Alberta Hospital, Edmonton, Alberta, Canada
}

\begin{abstract}
Inhaled nitric oxide has been reported to act as a specific pulmonary vasodilator. We used the newborn piglet to create acute hypoxic pulmonary hypertension and examined the effect of inhaled nitric oxide in this model. Six newborn piglets were instrumented in order to measure cardiac index, pulmonary arterial pressure, and systemic arterial pressure. Pulmonary hypertension was induced by reducing the fraction of inspired oxygen to 0.12 to 0.14 . With hypoxia (arterial oxygen saturation between 35 and $45 \%)$, pulmonary arterial pressure increased by $48 \%(p<$ $0.01)$, pulmonary vascular resistance increased by $74 \%(p$ $<0.01$, and both systemic arterial pressure and systemic vascular resistance decreased by 38 and $31 \%$, respectively $(p<0.01)$. The animals were then giving varying concentrations of inhaled nitric oxide between 5 and 80 parts per million in random order. All concentrations of nitric oxide were associated with a rapid decrease in pulmonary arterial pressure and pulmonary vascular resistance $(p<0.001)$. Cardiac index increased $(p<0.001)$ and systemic vascular resistance significantly decreased $(p=0.01)$ with all doses of inhaled nitric oxide. The ratio of pulmonary to systemic vascular resistance decreased with all levels of inhaled nitric oxide $(p<0.001)$. For all of the above observations there was no significant difference noted between the varying doses of nitric oxide. The time course of the pulmonary arterial pressure response to nitric oxide was approximately twice as fast as that seen with the inhalation of $100 \%$ oxygen $(10,50,90 \%$ responses of $4.1,8.8,88.6$ versus $6.7,51.9,197 \mathrm{~s}$, respectively; $p<0.01$ ). Inhaled nitric oxide at levels of 5 parts per million or greater reverses hypoxia-induced pulmonary vasoconstriction in the newborn piglet model. (Pediatr Res 35: 15-19, 1994)
\end{abstract}

\section{Abbreviations}

EDRF, endothelium-derived relaxing factor

$\mathrm{FiO}_{2}$, fraction of inspired oxygen

NO, nitric oxide

$\mathrm{NO}_{2}$, nitrogen dioxide

PAP, pulmonary arterial pressure

ppm, parts per million

PVR, pulmonary vascular resistance

$\mathrm{SaO}_{2}$, arterial oxygen saturation

SAP, systemic arterial pressure

SVR, systemic vascular resistance

Received April 6, 1993; accepted August 27, 1993.

Correspondence: Neil N. Finer, M.D., Royal Alexandra Hospital, 10240 Kingsway, Edmonton, Alberta, Canada TSH 3 V9.
There is now good evidence that at a cellular level vascular muscle tone is regulated in large measure by NO or an NOrelated compound, which is thought to be identical to the previously described EDRF (1-4). Nitroso-containing vasodilators, such as nitroprusside, are thought to act through liberating NO in tissue $(5,6)$. NO is synthesized by the vascular endothelium from L-arginine $(7,8)$, and acts through the stimulation of guanylate cyclase, leading to the production of cyclic GMP ( 9 , 10). The mechanism by which cyclic GMP relaxes vascular smooth muscle is not clear, but probably involves inhibition of activation-induced elevation in cytosolic calcium concentration (11).

Using a pulmonary hypertension model induced by the infusion of a thromboxane analog, heparin-protamine reaction, or hypoxia, Frostell, Fratacci and co-workers $(12,13)$ demonstrated reversal of pulmonary vasoconstriction using 40 to $80 \mathrm{ppm}$ of inhaled NO without significant effect on the systemic circulation in $25-$ to $35-\mathrm{kg}$ mature lambs. Similar results using pulmonary vasoconstriction produced by hypoxia with or without respiratory acidosis were obtained by Roberts et al. (14) who also demonstrated elevated plasma cyclic GMP levels after NO inhalation in a newborn lamb model. Kinsella et al. (15) evaluated the effects of NO in mechanically ventilated ovine fetuses maintained at intrauterine arterial oxygen levels. NO (5-20 ppm) produced an increase in pulmonary artery blood flow, an effect that was equal to the response seen when the $\mathrm{FiO}_{2}$ was increased to 1.0. In all of these studies there was no effect on the systemic circulation, specifically on SVR, and in two studies $(14,15)$ an increase in left-to-right shunting across the ductus occurred during NO inhalation, demonstrating that inhaled NO is a potent selective pulmonary vasodilator in these models.

The aims of the current study were to investigate the feasibility of administering NO to a neonatal model, i.e. the 1- to 2-d-old piglet, and to evaluate the dose response characteristics and the time course of the effect of NO on hypoxic pulmonary vasoconstriction.

\section{MATERIALS AND METHODS}

NO Administration. NO in nitrogen in a concentration of approximately $800 \mathrm{ppm}$ was obtained (Canadian Liquid Air, Montreal, Quebec). This source was certified to be $\pm 2 \%$ of the analyzed component (NO), and to contain $<5 \mathrm{ppm} \mathrm{NO}_{2}$. Singlestage stainless steel diffusion-free regulators were utilized and each regulator was flushed to ensure that any air or other byproducts such as $\mathrm{NO}_{2}$ were removed. This source gas was connected at a regulated pressure of 50 psi using Teflon tubing to the input port of a Matheson \#603 flowmeter (Matheson Gas Products Canada Inc., Edmonton, Alberta), and then injected at the desired flow rate into the inspiratory line of a time-cycled pressure-limited neonatal ventilator (Sechrist IV 100B, Sechrist Industries, Anaheim, CA), having a continuous gas flow of 12 
$\mathrm{L} / \mathrm{min}$. The resulting gas mixture was sampled downstream of the injection site and analyzed for $\mathrm{NO}, \mathrm{NO}_{2}$ and total oxides of nitrogen using a chemiluminescence analyzer (model $42 \mathrm{H}$, Thermo Environmental Instruments Inc., Franklin, MA). The concentration of $\mathrm{NO}_{2}$ was also checked using indicator tubes (Draeger tube $\mathrm{CH} 30001$, Draeger Canada Ltd., Mississauga, ON). Exhaled gas and exhaust from the analyzer was scavenged. The blender of the ventilator was connected to oxygen and nitrogen to enable the delivery of a hypoxic gas mixture.

Animal Preparation. Mixed strain newborn piglets were obtained on the first or second day of life. Initial anesthetic induction was by inhaled halothane $5 \%$, reduced to $2 \%$ when the animal was stable. A bolus of $20 \mu \mathrm{g} / \mathrm{kg}$ of fentanyl and $0.2 \mathrm{mg} /$ $\mathbf{k g}$ of acepromazine was given after tracheostomy surgery and insertion of a jugular venous line, followed by a continuous fentanyl infusion of $10 \mu \mathrm{g} / \mathrm{kg} / \mathrm{h}$. An incision in the right side of the neck allowed the insertion of a catheter through the external jugular vein into the right atrium, through which maintenance i.v. fluid of $30 \mathrm{~mL} / \mathrm{kg} / \mathrm{h}$ of $5 \%$ glucose was infused. A catheter was placed in the carotid artery for measurement of SAP. After the tracheostomy, halothane was discontinued, assisted ventilation was started, and paralysis was obtained using pancuronium bromide $(0.1 \mathrm{mg} / \mathrm{kg})$ every $45 \mathrm{~min}$. Further bolus doses of fentanyl $(5-10 \mu \mathrm{g} / \mathrm{kg})$ were administered as necessary. Through a left thoracotomy, a 6 - or 8-mm ultrasound flow probe (Transonics Inc., Rochester, NY) was placed around the pulmonary artery for measurement of cardiac output and 4- to 6-mm probe was also placed around the ductus arteriosus. A 22-gauge catheter was inserted into the root of the pulmonary artery through a purse string suture for the continuous measurement of PAP. The systemic and pulmonary catheters were connected to pressure transducers and together with the ECG signal, displayed on a neonatal monitor (model 78833B, Hewlett Packard, Waltham, MA). $\mathrm{SaO}_{2}$ was measured using a transcutaneous pulse oximeter (N200, Nellcor Inc., Hayward, CA). A continuous infusion of bicarbonate ( $15 \mathrm{mEq} / 100 \mathrm{~mL}$ of i.v. fluid) was given to prevent severe acidosis during the periods of hypoxia.

Procedure. After this instrumentation, the animal was allowed to rest for $20 \mathrm{~min}$ to ensure stability, which was defined as less than $5 \%$ variation in heart rate, SAP, and PAP over a 5-min period, and thereafter hypoxia was induced by reduction of the inspired oxygen concentration to 10 to $14 \%$ to produce a target $\mathrm{SaO}_{2}$ of 35 to $45 \%$. After the induction of hypoxia, a stable hypoxic baseline was obtained $(2 \mathrm{~min})$. An arterial blood specimen was obtained for the measurement of blood gases and methemoglobin.

NO was then administered according to a computer-generated random sequence in doses of $5,10,20,30,40,60$, or $80 \mathrm{ppm}$, maintaining the $\mathrm{FiO}_{2}$ at the same level. Administration of $\mathrm{NO}$ of greater than 20 to $30 \mathrm{ppm}$ was associated with a slightly lower $\mathrm{FiO}_{2}$, which was then readjusted to baseline.

Measurements were obtained at each dose when there were no further changes in PAP, $\mathrm{SaO}_{2}, \mathrm{SAP}$, or cardiac output, and the signals were recorded for $1 \mathrm{~min}$. An arterial blood specimen was drawn, the NO was discontinued, and a subsequent hypoxic baseline recorded. This procedure was repeated until all of the doses of NO had been administered. If the animal experienced significant hypotension (systolic arterial pressure decreasing to less than $60 \%$ of the hypoxic baseline) the hypoxia was terminated and the animal was allowed to recover before reintroducing hypoxia.

Data Acquisition. The physiologic parameters of interest were acquired through a personal computer (Dell 486/33, Dell Computer Corporation, Richmond Hill, $O N$ ) using an analog-todigital converter (DT2801, Data Translation Inc., Marlborough, MA). Software for acquisition analyses were written using Asyst Scientific Software System (Macmillan Software Co., New York, NY). With this software, continuous acquisition of the measured parameters was performed for a 2-min period at baseline, and a 1-min period after stability during each hypoxic NO exposure.
The computer-generated averages of the measured parameters were then utilized for subsequent analyses. The time response of the changes in PAP were similarly analyzed using the average values for each $1 \mathrm{~s}$ for the PAP to determine the time response of the change in the PAP compared to baseline. All signals were acquired at $24 \mathrm{~Hz}$. In order to compensate for the sampling delay time of the analyzer which was approximately $5 \mathrm{~s}$, initiation of the response was considered to be $5 \mathrm{~s}$ before the initial indication that the appropriate dose of NO had been measured by the analyzer.

Cardiac output was determined from the measurements of the calibrated ultrasonic flow probe. Cardiac index was calculated as cardiac output divided by the animal's weight in kilograms. SVR was calculated as mean SAP divided by cardiac index. PVR was calculated as the mean PAP divided by cardiac index.

Statistical Methods. The comparison of changes in the PAP with different doses of NO was evaluated using a randomized block design analysis of variance comparing both the dose of NO and the individual animal's responses. If a significant difference was determined, the intergroup differences were determined using the Student Newman Keuls method with a $p$ value of $<0.05$ being considered significant.

This protocol received the approval of the University of $\mathrm{Al}$ berta Animal Welfare Committee and all procedures performed during the experiment were within the guidelines established by Health and Welfare Canada for care of animals (16).

\section{RESULTS}

Six 1- to 2-d-old piglets were studied. The weight at the time of the study ranged from 1.2 to $1.8 \mathrm{~kg}$ with an average weight of $1.36 \mathrm{~kg}$. The mean normoxic and hypoxic baseline cardiovascular parameters are shown in Table 1 . With hypoxia, there was a significant increase in PAP and PVR (48 and 74\%; $p<0.01$ ), a significant decrease in SAP and SVR (38 and $31 \%$ respectively, $p<0.01$ ), and no significant change in cardiac index. The absolute changes in SAP and PAP are shown in Figure 1. The changes in PVR and SVR are shown in Figure 2.

With the administration of NO there was a significant decrease in PAP at all doses of NO ( $p<0.001$; Fig. 1). Although the maximal decrement appeared to be with $80 \mathrm{ppm}$, there were no significant differences in PAP between any of the NO doses other than with comparisons of each dose to baseline. SAP did not significantly change with NO. The PVR, which increased markedly with hypoxia, decreased with all doses of NO $(p<0.001)$ and there were no significant differences between the various doses of NO. The cardiac index increased at all NO doses $(p<$ 0.001 ) with no differences observed between the varying NO doses, and as a result, SVR decreased with each dose of NO ( $p$ $=0.01$ ). The ratio of PVR divided by SVR (Fig. 3) decreased significantly with each dose of NO $(p<0.001)$, but as for the other observations, there were no significant differences between the varying doses of NO. Flow through the ductus arteriosus was extremely low, so it was not possible to draw any conclusions regarding ductal shunting in this model.

The time course of the response of PAP to NO compared to $100 \%$ oxygen is shown in Figure 4. Two-way analysis of variance of these time responses showed a significant difference between the responses to oxygen and NO overall $(p<0.01)$, but no

Table 1. Hemodynamic measurements*

\begin{tabular}{lcc}
\hline & Normoxia & Hypoxia \\
\hline Cardiac index $(\mathrm{mL} / \mathrm{min} / \mathrm{kg})$ & $270 \pm 64$ & $250 \pm 66$ \\
SAP (mean; mm Hg) & $91 \pm 25$ & $57 \pm 15$ \\
PAP (mean; mm Hg) & $24 \pm 8$ & $35 \pm 8$ \\
PVR (mm Hg $\left.\cdot \mathrm{mL}^{-1} \cdot \mathrm{min} \cdot \mathrm{kg}\right)$ & $0.09 \pm 0.03$ & $0.16 \pm 0.09$ \\
SVR (mm Hg $\left.\cdot \mathrm{mL}^{-1} \cdot \mathrm{min} \cdot \mathrm{kg}\right)$ & $0.35 \pm 11$ & $0.24 \pm 0.07$ \\
PVR/SVR & $0.28 \pm .0313$ & $0.64 \pm 0.19$ \\
\hline
\end{tabular}

* Values are \pm SD. 


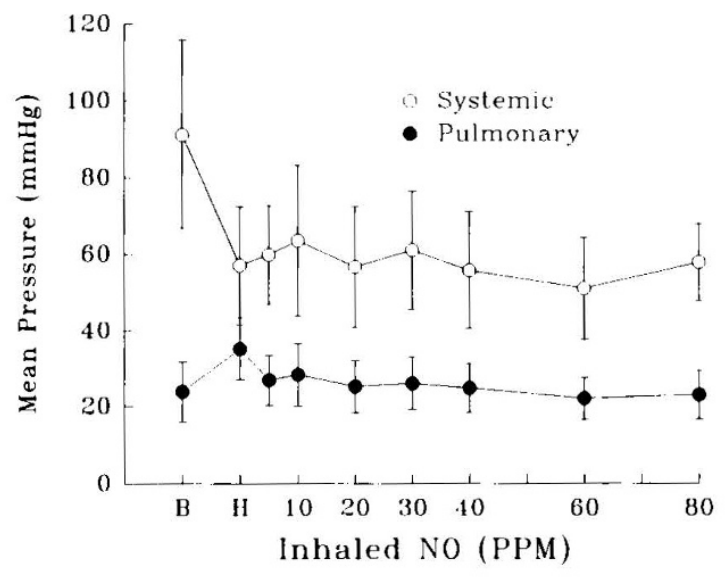

Fig. 1. SAP (open circles) and PAP (closed circles) (mean \pm SD) as a function of the administered concentration of $\mathrm{NO}(\mathrm{ppm})$. Abbreviations are: $\mathrm{B}$, baseline; $\mathrm{H}$, hypoxia with no $\mathrm{NO}$. Values for $\mathrm{H}$ are different from values for $\mathrm{B}$ for SAP and PAP, respectively (both $p<0.01$ ). PAP arterial pressures at all doses of inhaled NO are less than for $\mathrm{H}(p<0.001)$.

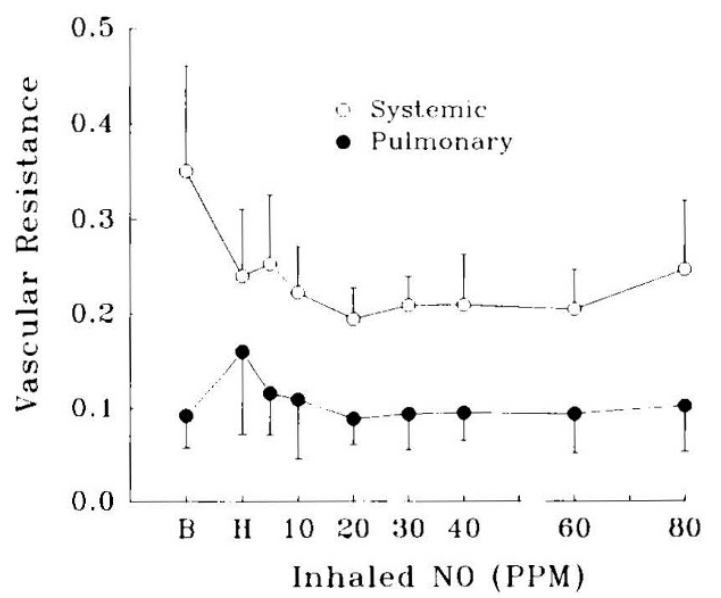

Fig. 2. SAR (open circles) and PVR (closed circles) vascular resistance $\left(\mathrm{mm} \mathrm{Hg} \cdot \mathrm{mL}^{-1} \cdot \mathrm{min} \cdot \mathrm{kg}\right.$; mean $\left.\pm \mathrm{SD}\right)$ as a function of the administered concentration of NO. Values for $\mathrm{H}$ are different from values for $\mathrm{B}$ for SVR and PVR, respectively (both $p<0.01$ ). PVR for all doses of inhaled $\mathrm{NO}$ are less than for $\mathrm{H}(p<0.001)$. SVR with NO is less than for $\mathrm{H}(p$ $<0.01$ ).

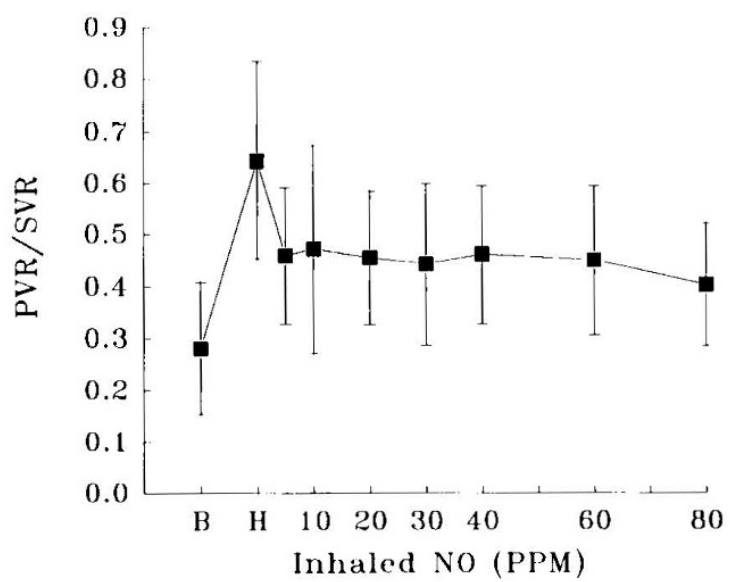

Fig. 3. The ratio of PVR to SVR (mean \pm SD) as a function of the administered concentration of NO. The ratio is less with each dose of NO than for $\mathrm{H}(p<0.001)$.

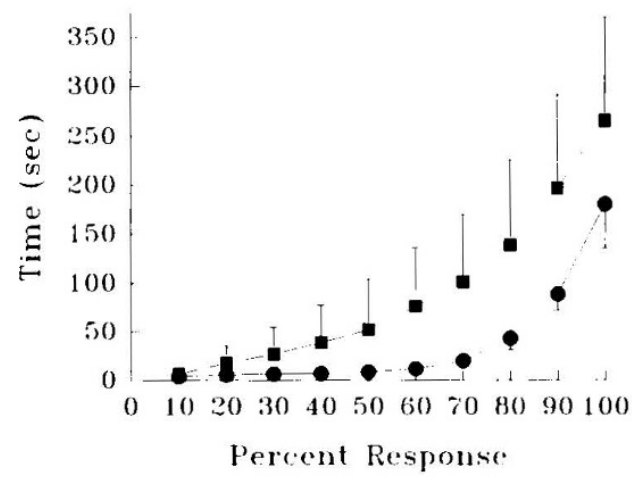

Fig. 4. Time elapsed (mean $\pm S D$ ) as a function of the percentage of full relaxation response of the PAP from hypoxic baseline. Closed squares, response to administration of $100 \%$ oxygen; closed circles, response to NO.

difference at individual selected points on the curve. The time intervals (mean \pm SD) for 10,50 , and $90 \%$ of the maximal response to $80 \mathrm{ppm}$ NO were $4.1 \pm 1.3,8.8 \pm 1.6$, and $88.6 \pm$ $16.5 \mathrm{~s}$, respectively; for the response to $100 \%$ oxygen the intervals were $6.7 \pm 5.5,51.9 \pm 52$, and $197 \pm 95 \mathrm{~s}$, respectively. The maximum methemoglobin concentration recorded with NO administration was $1.1 \%$.

\section{DISCUSSION}

In the newborn lamb (less than 1 wk of age) EDRF in part modulates resting pulmonary vascular tone and endotheliumdependent pulmonary vasodilation (17). Shaul et al. (18) showed that oxygen selectively modulates EDRF production and endothelium-dependent relaxation in isolated segments of ovine fetal intrapulmonary arteries. In the intact near-term ovine fetus, EDRF is responsible for the effect of acetylcholine on increasing pulmonary blood flow (19) and also, in large measure, mediates the increase in fetal pulmonary blood flow caused by an increase in oxygen tension $(20,21)$. Abman and co-workers (22) also studied the late gestation ovine fetus and showed that inhibition of EDRF production caused fetal pulmonary and systemic hypertension with attenuation of the increase in pulmonary blood flow at delivery. They also demonstrated that inhibition of NO formation attenuated the pulmonary vasodilation produced by ventilation, increasing oxygen tension and shear stress (23) and that inhalation of NO by the ovine fetus caused sustained and selective pulmonary vasodilation (15).

Using the newborn lamb model, Zapol and co-workers showed that inhaled NO reversed acute pulmonary vasoconstriction produced by hypoxia, a thromboxane analog, or by the heparinprotamine reaction $(12,13)$. Roberts $e t$ al. $(14)$ also found that the presence or absence of hypercarbia did not affect the pulmonary vasodilation produced by inhaled NO in this same model. The inhaled NO binds to the iron of heme-proteins (24) including hemoglobin to form nitrosyl hemoglobin which is rapidly oxidized to nitrite, nitrate, and methemoglobin $(25,26)$. As a result, inhaled NO exerts its effect exclusively on the pulmonary blood vessels of ventilated lung without any significant effect on the systemic circulation. No investigators to date have noted any significant accumulation of methemoglobin using up to $80 \mathrm{ppm}$ of inhaled NO, nor any effects on systemic blood pressure.

The present study extends these observations to the newborn piglet with hypoxia-induced pulmonary hypertension. Our results are consistent with previous studies in the lamb model (1215 ) in that a prompt reduction of hypoxia-induced pulmonary hypertension is seen with the inhalation of NO in concentrations as low as $5 \mathrm{ppm}$. The previous studies in the lamb model demonstrated a dose response to inhaled NO; for example Roberts $e t$ al. (14) in a study of seven lambs at approximately $140 \mathrm{~d}$ 
gestational age, demonstrated that the response to $80 \mathrm{ppm}$ inhaled NO was significantly greater than that seen at $20 \mathrm{ppm}$. Although there does appear to be a consistent maximal effect with $80 \mathrm{ppm}$ in the newborn piglet, we found no statistical advantage in going beyond $5 \mathrm{ppm}$ in terms of the absolute decrease in PAP and reduction in PVR. The PVR/SVR ratio was also significantly reduced from baseline with each dose of $\mathrm{NO}$, the maximum decrease being seen at $80 \mathrm{ppm}$, but again there were no significant differences between the varying doses of NO. It may be that there are species differences in the dose response to inhaled NO, or more likely, it may be that our failure to demonstrate a significant incremental dose response is due to the small number of animals studied.

Comparison of the time course of the PAP response to NO with that to $100 \%$ oxygen demonstrates a significantly faster response to NO. With oxygen, $90 \%$ of the total response occurred on average after $197 \mathrm{~s}$, compared with $89 \mathrm{~s}$ for NO. It seems likely that the more rapid time course of pulmonary vasodilation observed in our piglet model with the inhalation of NO when compared with inhalation of oxygen, is due to the direct effect of NO diffusion to the smooth muscle cells of the small pulmonary arteries, whereas inhaled oxygen acts through the generation of endogenous EDRF in the endothelium, which then has to diffuse to the muscle cell.

This is the first study of inhaled NO using the newborn piglet model, which raises the question of the suitability of this model. Zellers and Vanhoutte (27) have demonstrated that rings of piglet pulmonary arteries demonstrate endothelium-dependent relaxation and that artery rings from which the endothelium had been removed respond to NO. In addition, the oxygen dissociation curves of human and porcine blood are similar in shape, although the porcine curve lies to the right of the human, so that the newborn piglet would seem to be a reasonable model for the human situation (28).

In experiments on anesthetized dogs, Greenbaum et al. (29) reported that inhalation of $2 \% \mathrm{NO}$ or $\mathrm{NO}_{2}$ resulted in death due to methemoglobinemia, hypoxemia, and pulmonary edema. Using an adult rat model, Stavert and Lehnert (30) found that exposure of up to $1500 \mathrm{ppm}$ of NO for $15 \mathrm{~min}$ or $1000 \mathrm{ppm}$ NO for 30 min produced no detectable histopathologic change in the lungs, although rats exposed to $1000 \mathrm{ppm}$ for $30 \mathrm{~min}$ became cyanotic and died due to methemoglobinemia. Exposure to 50 ppm $\mathrm{NO}_{2}$ for 30 min produced an increase in lung weight, and histologic evidence of lung injury was observed after 30 -min exposures to $25 \mathrm{ppm}$ of $\mathrm{NO}_{2}$, but not at lesser exposure concentrations and times. The main concerns with toxicity, therefore, are methemoglobinemia due to NO, and direct pulmonary injury due to $\mathrm{NO}_{2}$. Because $\mathrm{NO}$ is oxidized in the presence of oxygen to $\mathrm{NO}_{2}$, it is important to be aware of the time course of this reaction, for which some guidelines have been published (31). Monitoring for $\mathrm{NO}_{2}$ concentrations close to the subject's airway is also necessary. Methemoglobin levels must also be carefully measured, and it is encouraging that to date in humans there have been no reports of serious methemoglobinemia.

This study which was done in 1- to 2-d-old neonatal piglets, an animal model which has similar cardiovascular physiology to the neonate, suggests that the human neonate with reversible pulmonary hypertension may well respond to inhaled NO in doses as low as $5 \mathrm{ppm}$ in keeping with the preliminary results of Kinsella et al. (32). As the full spectrum of toxicity of inhaled NO is not yet determined, it would seem that further clinical trials involving inhaled NO clinically should evaluate doses as low as $5 \mathrm{ppm}$ to avoid accumulation of $\mathrm{NO}_{2}$ and other toxic derivatives of NO. Inhaled NO has now been demonstrated to be beneficial in adults with pulmonary hypertension $(33,34)$, adults with adult respiratory distress syndrome (35), children with pulmonary hypertension associated with congenital heart disease (36), and neonates with persistent pulmonary hypertension of the newborn $(32,37)$. No controlled studies, however, have yet demonstrated any effect on outcome, nor on long-term morbidity, and such studies are required before inhaled NO becomes an accepted clinical form of therapy.

Acknowledgments. The technical help of Rob McKinley BMET, Rosanne Wieben RRT, Barbara Kamstra RN, Brenda Young RN, and Aston Hugh BSc, is gratefully acknowledged. Dr. D. Kita of Thermo Environmental Instruments Inc. provided invaluable advice and support.

\section{REFERENCES}

1. Ignarro LJ 1989 Biological actions and properties of endothelium-derived nitric oxide formed and released from artery and vein. Circ Res 65:1-21

2. Furchgott RF, Vanhoutte PM 1989 Endothelium-derived relaxing and contracting factors. FASEB J 3:2007-2018

3. Palmer RMJ, Ferrige AG, Moncada S 1987 Nitric oxide release accounts for the biological activity of endothelium-derived relaxing factor. Nature 327:524-526

4. Ignarro L, Buga GM, Wood KS, Byrns RE, Chaudhuri G 1987 Endotheliumderived relaxing factor produced and released from artery and vein is nitric oxide. Proc Natl Acad Sci USA 84:9265-9269

5. Gruetter CA, Barry BK, McNamara DB, Gruetter DY, Kadowitz PJ, Ignarro LJ 1979 Relaxation of bovine coronary artery and activation of coronary arterial guanylate cyclase by nitric oxide, nitroprusside and a carcinogenic nitrosoamine. J Cyclic Nucleotide Res 5:211-224

6. Bassenge E 1992 Clinical relevance of endothelium-derived relaxing factor (EDRF). Br J Clin Pharmacol 34(Suppl): 37S-42S

7. Marsden PA, Schappert KT, Chen HS, Flowers M, Sundell CL, Wilcox JN, Lamas S, Michel T 1992 Molecular cloning and characterization of human endothelial nitric oxide synthase. FEBS Lett 3:287-293

8. Palmer RMJ, Rees DD, Ashton DS, Moncado S $1988 \mathrm{~L}$-arginine is the physiological precursor for the formation of nitric oxide in endothelium. dependent relaxation. Biochem Biophys Res Commun 153:1251-1256

9. Burke-Wolin T, Abate CJ, Wolin MS, Gurtner GH 1991 Hydrogen peroxideinduced pulmonary vasodilation: role of guanosine 3',5'-cyclic monophosphate. Am J Physiol 261:L393-L398

10. Gruetter CA, Gruetter DY, Lyon JE, Kadowitz PJ, Ignarro LJ 1981 Relationship between cyclic guanosine $3^{\prime}: 5^{\prime \prime}$-monophosphate formation and relaxation of coronary arterial smooth muscle by glyceryl trinitrate, nitroprusside, nitrite, and nitric oxide: effects of methylene blue and methemoglobin. $J$ Pharmacol Exp Ther 219:181-186

11. Walter U 1989 Physiological role of cGMP and cGMP-dependent protein kinase in the cardiovascular system. Rev Physiol Biochem Pharmacol 113:42-88

12. Frostell C, Fratacci MD, Wain JC, Jones R, Zapol WM 1991 Inhaled nitric oxide: a selective pulmonary vasodilator reversing hypoxic pulmonary vasoconstriction. Circulation 83:2038-2047

13. Fratacci MD, Frostell CG. Chen TY, Wain JC, Robinson DR, Zapol WM 1991 Inhaled nitric oxide-A selective pulmonary vasodilator of heparinprotamine vasoconstriction in sheep. Anesthesiology 75:990-999

14. Roberts JD, Chen TY, Kawai N, Wain J, Dupuy P, Shimouchi A, Bloch K. Polaner D, Zapol WM 1993 Inhaled nitric oxide reverses pulmonary vasoconstriction in the hypoxic and acidotic newborn lamb. Circ Res 72: 246-254

15. Kinsella JP, McQueston JA, Rosenberg AA, Abman SH 1992 Hemodynamic effects of exogenous nitric oxide in ovine transitional pulmonary circulation. Am J Physiol 263:H875-H880

16. Canadian Council on Animal Care 1984 Guide to the Care and Use of Experimental Animals, Vol 1. Ottawa

17. Fineman JR, Heymann MA, Soifer SJ 1991 N-nitro-L-arginine attenuates endothelium-dependent pulmonary vasodilation in lambs. Am J Physiol 260:H1299-H1306

18. Shaul PW, Farrar MA, Zellers TM 1992 Oxygen modulates endotheliumderived relaxing factor production in fetal pulmonary arteries. Am J Physiol 262:H355-H364

19. Tiktinsky MH, Cummings JJ, Morin FC III 1992 Acetylcholine increases pulmonary blood flow in intact fetuses via endothelium-dependent vasodilation. Am J Physiol 262:H406-H410

20. Morin FC III, Tiktinsky MH 1992 Oxygenation increases fetal pulmonary blood flow via endothelium dependent vasodilation. Pediatr Res 31:237A(abstr)

21. Moore P, Velvis H, Fineman JR, Soifer SJ, Heymann MA 1992 EDRF inhibition attenuates the increase in pulmonary blood flow due to oxygen ventilation in fetal lambs. Am J Physiol 73:2151-2157

22. Abman SH, Chatfield BA, Hall SL, McMurtry IF 1990 Role of endotheliumderived relaxing factor during transition of pulmonary circulation at birth. Am J Physiol 259:H1921-H1927

23. Cornfield DN, Chatfield BA, McQueston JA, McMurtry IF, Abman SH 1992 Effects of Birth-related stimuli on L-arginine-dependent pulmonary vasodilation in ovine fetus. Am J Physiol 262:H1474-H1481

24. Ignarro LJ, Adams JB, Horwitz PM, Wood KS 1986 Activation of soluble guanylate cyclase by NO-hemoproteins involves NO-heme exchange. J Biol Chem 261:4997-5002 
25. Yoshida K, Kasama K 1987 Biotransformation of nitric oxide. Environ Health Perspect 73:201-206

26. Wennmalm A, Benthin G, Petersson AS 1992 Dependence of the metabolism of nitric oxide (NO) in healthy human whole blood on the oxygenation of its red cell haemoglobin. Br J Pharmacol 106:507-508

27. Zellers TM, Vanhoutte PM 1991 Endothelium-dependent relaxations of piglet pulmonary arteries augment with maturation. Pediatr Res 30:176-180

28. Kamal GD, Start JM, Symreng T 1990 Continuous, in vivo pulmonary venous admixture from fiberoptically measured hemoglobin saturations. Crit Care Med 18:1419-1422

29. Greenbaum R, Bay J, Hargreaves MD, Kain ML, Kelman GR, Numm JF, Prys-Roberts C, Siebold K 1967 Effects of higher oxides of nitrogen on the anaesthetized dog. Br J Anaesth 39:393-404

30. Stavert DM, Lehnert BE 1990 Nitric oxide and nitrogen dioxide as inducers of acute pulmonary injury when inhaled at relatively high concentrations for brief periods. Inhalation Toxicol 2:53-67
31. Foulbert L, Fleming B, Latimer R, Jonas M, Oduro A, Borland C, Higenbottam

T 1992 Safety guidelines for use of nitric oxide. Lancet 339:1615-1616
32. Kinsella JP, Neish SR, Shaffer E, Abman SH 1992 Low-dose inhalational nitric oxide in persistent pulmonary hypertension of the newborn. Lance 340:819-820

33. Pepke-Zaba J, Higenbottam TW, Dinh-Xuan AT, Stone D, Wallwork J 199! Inhaled nitric oxide as a cause of selective pulmonary vasodilation in Inhaled nitric oxide as a cause of selective pulm
pulmonary hypertension. Lancet $338: 1173-1174$

34. Girard C, Lehot JJ, Pannetier JC, Filley S, Ffrench P, Estanove S 1992 Inhaled nitric oxide after mitral valve replacement in patients with chronic pulmonary artery hypertension. Anesthesiology 77:880-883

35. Rossaint R, Falke KJ, Lopez F, Slama K, Pison U, Zapol WM 1993 Inhaled nitric oxide for the adult respiratory distress syndrome. $N$ Engl $\mathrm{J}$ Med 328:399-405

36. Roberts JD, Lang P, Bigatello LM, Vlahakes GJ, Zapol WM 1993 Inhaled nitric oxide in congenital heart disease. Circulation 87:447-453

37. Roberts JD, Polaner DM, Lang P, Zapol WM 1992 Inhaled nitric oxide in persistent pulmonary hypertension of the newborn. Lancet 340:818-819

\section{Announcement}

\section{THE ASSOCIATION OF MEDICAL SCHOOL PEDIATRIC DEPARTMENT CHAIRMEN, INC. proudly announces the Pediatric Scientist Development Program 1993 Fellows}

Name

Ari J. Bergwerk, M.D.

Patricia Ann DeRusso, M.D.

Cheryl Ann Gale, M.D.

Anna Huttenlocher, M.D.

Andrew Mark Scharenberg, M.D.

Thomas Shanley, M.D.

Deepak Srivastava, M.D.

James A. Thomas, M.D.
Sponsoring Department and Chairman

Michael Cohen, M.D. Albert Einstein College of Medicine

Elias Schwartz, M.D. Children's Hospital of Philadelphia

Harvey R. Colten, M.D. Washington University

Larry J. Shapiro, M.D. University of California, San Francisco

Thomas F. Boat, M.D. University of North Carolina, Chapel Hill

Elias Schwartz, M.D. Children's Hospital of Philadelphia Larry J. Shapiro, M.D. University of California, San Francisco

Robert L. Baehner, M.D. Children's Hospital of Los Angeles

We gratefully acknowledge the support and sponsorship of

National Institute for Child Health and Human Development March of Dimes Birth Defects Foundation

St. Jude Children's Research Hospital American Academy of Pediatrics

Cystic Fibrosis Foundation

The Hospital for Sick Children Foundation American Pediatric Society

The Burroughs Wellcome Fund 